\title{
Why 'Swampman' would not even get as far as thinking it was Davidson: On the spatio-temporal basis of Davidson's conjuring trick
}

Abstract: In this article we analyse one of the most famous recent thoughts-experiments in philosophy, namely Donald Davidson's Swampman. Engaging recent commentators on Davidson's Swampman as well as analysing the spatio-temporal conditions of the thought-experiment, we will show how the 'experiment' inevitably fails. For it doesn't take seriously some of its own defining characteristics: crucially, Swampman's creation of a sudden in a place distinct from Davidson's. Instead of denigrating philosophical thought-experiments per se, our analysis points towards considering thought-experiments in a different sense: imaginary scenarios helpfully selfdeconstructing rather than constituting substantive philosophical resources.

Keywords: Donald Davidson, Swampman, Wittgenstein, externalism, time/space

"Suppose lightning strikes a dead tree in a swamp; I am standing nearby. My body is reduced to its elements, while entirely by coincidence (and out of different molecules) the tree is turned into my physical replica. My replica, Swampman, moves exactly as I did according to its nature, it departs the swamp, encounters and seems to recognise my friends, and appears to return their greetings in English. It moves into my house and seems to write articles on radical interpretation. No one can tell the difference." Donald Davidson ${ }^{1}$

\section{Introduction}

In telling this shortest of science-fiction stories, Donald Davidson means - and he makes this explicit in his famous article - to carve out a position on 1stperson knowledge that is distinct from (though related to) those of Putnam and of Wittgenstein. He claims to be more 'internalist' than they, though simultaneously to be taking seriously the logic of 'externalism'. The latter point is clear in Davidson ${ }^{2}$ continuing:

"But there is a difference [between Swampman and Davidson]. My replica can't recognize my friends; it can't recognize anything, since it never cognized anything in the first place...I don't see how my replica can be said to mean anything by the sounds it makes, nor to have any thoughts."

\footnotetext{
${ }^{1}$ Davidson (2001b, 19).

${ }^{2}$ Op.cit.
} 
Davidson quite explicitly holds that Swampman's having the wrong casual history deprives him of any technical right to be a site of "cognition", external appearances to the contrary notwithstanding. Thus, Davidson on the one hand has Swampman fully appear to be Davidson - he thinks that this follows from their physicalist identity - while on the other hand he thinks that the proper application of terms such as "recognize" must be withheld from application to what Swampman (qua Davidson) does. (And there is surely something right about this last point. According to Davidson's hypothesized situation, no-one would ever know it; but, from a God's eye point of view - if one thinks it OK to postulate such a point of view, which is, we think, an open question Swampman seems fairly clearly to have false memories.)

That sounds quite a radical substantive philosophical position, quite strongly and originally 'non-individualist'. But what Wittgenstein ${ }^{3}$ famously advised, when looking at philosophers' 'thought-experiments', is: to watch out for what is already conceded prior to any substantive explicit philosophical claim:

\section{"The decisive moment of the conjuring trick has been made, and it was the very one that we thought quite innocent ${ }^{44}$}

We wish to suggest that Davidson has already allowed far too much, without even realising it, when he allowed that the successful creation of his replica, Swampman, in the manner in which he posits it, is so much as possible. Our point here is not about physical possibilities; we are not denying that in some sense it is quantum-possible for something that looks superficially like Swampman (i.e. something that looks like Davidson!) to be created: we wish, rather, to examine more closely the spatio-temporal conditions of normal experience taken for granted in Davidson's writing as well as by most commentators on Swampman. Doing so, we think one can see that everyone will be able to tell the difference between Swampman and Davidson on inspection. Swampman, then, will actually never be able to take off in the first place, instead being disclosed as what it is, a conjuring trick.

Swampman may literally never succeed in realising anything. Davidson has Swampman in some technical sense not have thoughts, while continuing to lead a normal life in which no-one can tell the difference between him and Davidson. However, what we are saying is that, Swampman risks being born radically insane. If, indeed, he is capable of being 'born' at all; we shall also raise doubts about whether the simultaneous (to Davidson's extinction) creation of Swampman is (not so much physically but) conceptually possible, meaningful.

In the following we will first discuss some recent interpretations of Swampman, deepening our understanding of what is taken for granted in Davidson's

\footnotetext{
${ }^{3}$ Wittgenstein (2001).

${ }^{4}$ Wittgenstein $(2001, \S 308)$.
} 
example. We will then analyse Swampman, focusing on the spatiotemporal framework assumed as the main reason why Swampman is not logically or phenomenologically credible.

\section{Interpretations of Swampman}

Let us begin by taking a step back, and noting how, since Davidson's publication thereof, the Swampman thought experiment has been discussed and interpreted widely. Of special interest to us will be how the spatiotemporal element has been interpreted (see section 3, below). Our point of departure here will therefore be one of the best systematic interpretations of Swampman, by Ernie Lepore and Kirk Ludwig ${ }^{5}$ supported with Kallestrup ${ }^{6}$, relating the thought experiment to the debate on externalism-internalism and historical time as a frame for knowledge uptake.

At the basis of Davidson's example is two presuppositions. The first is that of physical identity between Davidson and Swampman. Davidson frames Swampman argumentatively in a discussion of Putnam's notion of meanings 'just ain't in the head' (Putnam 1975, 227), the conclusion of which is "...that aspects of the natural history of how someone learned the use of a word necessarily make a difference to what the word means. It seems to follow that two people might be in physically identical states, and yet mean different things by the same words." (Davidson 2001b,18) Davidson wants to provide his own example of this - he thinks people might be weary of Putnam's doppelgänger earth - which is Swampman (as if Swampman couldn't be an object of weariness, as Davidson himself seems to have discovered over the subsequent years ${ }^{7}$ ). So, in describing Swampman he uses talk of molecules to enforce the description of a physically identical state between Davidson and Swampman.

The second presupposition follows from the first, namely that Swampman is created at the same moment as, or simultaneously (Kallestrup 2012, 79) with Davidsons' expiring. Emphasising physical identity wouldn't make sense if Swampman and Davidson were present, even partly, at the same time. If such co-presence was intended to be the case wouldn't Davidson, hypothetically speaking, have been better off using twins as an example instead? Also, would Putnam's twin-earth make sense, if earthlings and twin-earthlings were located at the same place?

\footnotetext{
${ }^{5}$ Lepore and Ludwig (2005).

${ }^{6}$ Kallestrup (2012).

${ }^{7}$ Cf. note 27 below.
} 
Both presuppositions, then, serve as the context for Davidson's discussion of externalism vs. internalism.

Externalism in general holds that the content of at least some of our thoughts depend upon our having some sort of relation to the environment. Theories of externalism differ in terms of asking what kind of relation and what kind of environment it is, our thoughts depend upon.

Broadly speaking, the relation can be understood on a spectrum running from a pure causal kind often called naturalistic or nomic in one end, towards a norm-induced behaviour often termed normative in the other. Davidson tries to position himself in the middle combining the causal and normative relation in what he terms anomalous monism ${ }^{8}$. Basically, the anomalous condition consists in combining (or rather considering as a whole, i.e. monism) a causal interaction between the mental and the physical while still claiming that this causal interaction cannot be of a solely nomic, or lawlike character. So, my wanting cheese causes a certain change in a local area of space-time due to my heading towards the cheese-shop, but there is no strict law covering the string of actions, the events, effected by my wanting to go to the cheese-shop. Normative constraints like consistency in actually getting to the shop, and coherence in justifying the choices made along the way are part of the interaction, but cannot be adequately described by referring to physical laws. Hence, Davidson claims, the mental, my thinking and wanting to go for cheese, cannot be reduced to, or explained solely by appeal to laws determining physical events. And this goes for the physical make-up of me as well; thinking cannot be reduced to brain-waves (or genes) either. Instead the mental and the physical can be paired or correlated to one another; the description of a mental event's consistency and coherence can be correlated with a physical description of the same event.

It should come as no surprise then, that Davidson is critical of externalist theories with a more naturalistic reductionist bend (his target here is traditional physicalism ${ }^{9}$ ) as well as theories considering the social environment (the target here is the motley crew of Burge, Putnam, Dennett, and Stich) as the primary basis of interaction. The overall point of the thought experiment is, therefore, that despite Swampman being a physical replica of Davidson, Swampman's mental life, the possibility of his knowing his own mind, cannot be identical to Davidson's, because the mental is irreducible to the physical. Furthermore, Swampman lacks Davidson's exact history of physically interacting with the surrounding world, and has therefore no access to whatever effects of the normative constraints Davidson has experienced through his life. Davidson claims:

\footnotetext{
8 Davidson (1970).

9 Davidson (2001, 25).
} 
"What I take Burge's and Putnam's imagined cases to show (and what I think the Swampman example shows more directly) is that people who are in all relevant physical respects similar...can differ in what they mean or think, just as they can differ in being grandfathers or being sunburned. But of course there is something different about them, even in the physical world; their causal histories are different, and they are discrete physical objects." (2001b, 32-33)

Hence, for Davidson externalism is connected to time through considering the interactions with the world as unfolding in time. But how are we to understand this?

Lepore and Ludwig ${ }^{10}$ distinguish between a diachronic and synchronic externalism. The latter holds that the contents of our thoughts are related and dependable only on the basis of the current environment including whatever dispositions we possess responding to it. Unlike the former, which claims the past of our causal interactions with the environment to be central to establishing our thought-contents and that there continues always to be a line of influence from the present to the past, the latter denies that this content implies any significant historical facts about us, but only facts about our potentialities relating to our present environment. For Lepore and Ludwig the distinction brings out a certain tension in Davidson's position between his notion of radical interpretation ${ }^{11}$ which is present-oriented and a-historicist, and Swampman which exemplifies something more like a diachronic externalist position where meaning is a historical phenomenon ${ }^{12}$.

For Davidson the radical interpreter epitomizes the idea of creating a theory of meaning, i.e. presenting the conditions for the truth of a sentence in an objectlanguage, using Tarski inspired biconditionals, T-sentences, to interpret the meaning of speakers whom the interpreter has no knowledge of beforehand. The interpreter does this by correlating the sentences made by these speakers with aspects of the external environment common to both the interpreter and the speaker. To succeed the interpretation must, for Davidson, be charitable, i.e. it must presuppose the interpreter holds the beliefs of herself and the speaker whom she interprets as mostly true. In this sense the principle of charity aims at maximizing agreement between interpreter and speaker, while still allowing for the possibility of failure, i.e. of occasional misunderstandings. The problem is, then, that all the radical interpreter needs, to understand a speaker, is to correlate the meaning of this speaker's sentences, sentences the speaker holds to be true, with the features of the environment prompting the utterance of these sentences. Only these features and the speaker's

\footnotetext{
${ }^{10}$ Lepore and Ludwig (2005, 336f).

11 Davidson (1981).

12 See also Kallestrup (2012, 84-85).
} 
responsive dispositions to react to these, matter; any knowledge about the speaker's history of learning the meaning of words comprising the uttered sentences can be disregarded. And since Davidson and Swampman are identical in a physical sense, the radical interpreter should also be able to understand Swampman - correlating Swampman's sentences with environment working the principle of charity. But of course, he cannot do that, for Swampman has no history of physical interaction with the environment, at least not in the interval between the time/space where Swampman pops up (A) and a given time/space-point afterwards (B), when Swampman might begin to establish a history of engaging the environment needed for creating meaningful thoughts and language. Swampman will never be able to recognize Davidson's friends as Davidson does, because Swampman and Davidson are not historical duplicates. But the radical interpreter will still interpret Swampman as recognizing Davidson's friends as Davidson's does, because the understanding is based on Swampman's relation to the immediate environment in the present situation, the moment in which the recognition takes place.

Now this potential tension can, according to Lepore and Ludwig $^{13}$ be resolved by just combining the radical interpretation with some sort of historical component. We assume that Lepore and Ludwig understand this component as resembling a linear understanding of time (we will return to this below), since they present the component as a summation, as adding enough past causal and spatial interactions with an environment (from A to B above) for grounding Swampman's thoughts about things in general. However, leaving the element of time at this would, Lepore and Ludwig claim, divert our attention from a deeper problem: "Rather, the problem is that this historical component looks to require a grounding different from, say, the appeal to decision theory as providing a basic framework for attitude attribution, since it is not tied up with our conception of the patterns of attitudes which are required for agency". ${ }^{14}$ What Lepore and Ludwig indicate here is, that if this historical component is to be added to the framework of radical interpretation, it would require a different grounding than the appeal to the attitude of a speaker holding sentences to be true, supposed in radical interpretation. And working out this grounding, Davidson would actually have to give up the idea of radical interpretation to entertain a sense of historical externalism. Hence, they claim "It looks as if this additional requirement...to some extent undercuts the view that the radical interpreter's standpoint is basic." ${ }^{15}$ Now this seems to be based on a specific view of time (and space) making this possible, namely a linear view of consecutive space-time points. Hence, considering different views on spacetime might open up different possibilities of interpreting and critiquing Davidsons' position.

\footnotetext{
${ }^{13}$ Lepore and Ludwig $(2005,338)$.

14 Op.cit.

15 Op.cit.
} 
Despite this being, from our point of view, a fairly precise diagnosis of what the Swampman thought experiment is actually disclosing, Lepore and Ludwig do not follow up on what this deeper, different, diachronic or historical grounding could mean, besides their suggestion of a summative linear time component of past causal interactions. Instead they conclude that Swampman on the face of it is a non sequitur, hence without any persuasive force, implying therefore it should be disregarded (and with it the idea of a historical externalism) to restore consistency to Davidson's philosophy ${ }^{16}$

To reiterate, within Lepore and Ludwig's presentation of Davidson we can discern two frameworks for understanding how temporal considerations can be important in their interpretation of Swampman, one explicit and one implicit. The first consisted of the linear picture of time made up of consecutive slices together serving as a historical ground for the possibility of an agent having general thoughts. This was the one Davidson would have to leave to uphold the idea of radical interpretation, preserving the synchronic externalist and decision-making oriented framework. The second was the possibility, which neither Lepore and Ludwig (nor Davidson for that matter) touches upon, of understanding the grounding of the historical component as not based on purely a linear-sequential understanding of time. The failure to consider this possibility indicates a failure to understand Swampman as genuinely (needing to be - and unable to be) contextualised in time as well as space, with the philosophical implications this should have. It is as if, despite the fact that the thought-experiment is supposed to happen in 'regular' swamp-like surroundings involving time and space, the interpretation fails seriously to consider this, giving the experiment an even more abstract character than it already possesses.

\section{Contextualising Swampman: time and space matters}

Let us now explain how we see the thought experiment differently. Essentially, we think that Davidson's interpreters fail to take the diachronic seriously enough (in this, they follow Davidson, who, as we saw in section 2 above, is of two minds on this); and that they fail also to take the question of spatial-location (i.e. of place or placement) seriously enough.

As we saw above the crucial point about Swampman is that he and Davidson are 'molecule for molecule' 'identical'. This form of identity of brains and bodies - what Davidson calls "physically identical states" - is allegedly enough for them to act the same way and to seem to have the same thoughts, etc. But now, note a respect in which they aren't identical: they can't be in the same

\footnotetext{
${ }^{16}$ Lepore and Ludwig (2005, 339).
} 
place. One is in one part of the swamp, when he is killed; the other finds himself in another part of the swamp, when he is suddenly brought into existence.

Consider two identical molecules; we say that they are identical, and it is fine - it doesn't cause our saying to somehow go awry - that they are not in the same place: because place generally doesn't matter in physics ${ }^{17}$ as it does matter, profoundly, in socio-psychological life.

Or again: Consider two identical molecules; but one of them is in motion, and the other isn't. Or indeed, let's go further: one of them is accelerating and the other isn't (their velocity at the point-time in question might be the same: but there is still a difference between them). From a dimensionless time-slice, one wouldn't know that there is this crucial difference between them. Similarly, metaphorically (or indeed perhaps literally) Swampman is stationary while we are perhaps in motion / accelerating. It makes no sense to think of Swampman as in motion or acceleration at the very moment of his creation - because a thing can only be in motion over time, and, at the very moment of his creation, Swampman is not in time. At the instant of Davidson's death, Swampman 'springs' into existence. A dimensionless time-slice leaves out crucial features even of a molecule - let alone of a complex being. Being 'identical' at a dimensionless time-slice - a concept, an idea that is needed, to make sense of being brought of a sudden fully into existence - is not being identical in these crucial respects.

This point of ours perhaps invites the objection that Davidson claims that Swampman is physically identical, and, since motion is part of a physical specification, by hypothesis Davidson and Swampman cannot be distinguished in the way we suggest - they would otherwise have different physical individuation criteria. But is this correct? We think not. The dimensionless-timeslice conception of the universe ${ }^{18}$ without which Davidson's way of setting out the situation cannot be sustained, takes a 'pure' 'infinitely thin' snapshot of the universe in which there is no motion or acceleration. Except insofar as motion or acceleration is 'registered' in molecules by way of them being deformed slightly in shape or what-have-you (and such deformations could in theory arise having the same appearance in particles not in motion), it would not show up in such a time-slice. In any case, even if this objection were correct, it wouldn't much matter to our argument; for what we need for our argument to go through is only what we termed above the metaphorical sense of the point. The metaphorical sense in which Swampman may not be in motion as we are, is what matters. We are in motion through time, as it were, in the course of normal

\footnotetext{
${ }^{17}$ Strictly speaking, of course, even this isn't true. Since General Relativity, place has been 'back' in physics, in a somewhat-similar way to its presence in physics in the Ancient world. See e.g. Kuhn (1970). There is a sense in which no molecules at all are identical with each other, just by virtue of being spatially-differentiated. However, it is unlikely that this sense would literally matter, at the level of personal identity (change), etc.

${ }^{18}$ See for example (Read 2003).
} 
existence, including in the Present. Whereas, at the instant of his creation, Swampman is not. We'll briefly explain this point further now by reference to James and Bergson:

As William James understood, 'The present' is not actually a dimensionless time-slice, but is rather characterised as a specious present, "...the short duration of which we are immediately and incessantly sensible." ${ }^{19}$. [Similarly, a 'moment' is not a dimensionless time-slice, if the term 'moment' is to have any phenomenological meaning whatsoever.] A being brought of a sudden into existence does not at first exist in the present. At the instant of its creation, Swampman, though molecule for molecule identical with Davidson, does not exist in the present. The present is minimally something like a 'durée', in roughly Bergson's sense. ${ }^{20}$ One's 'motion' or 'acceleration' through it is crucial.

Swampman is dumped of a sudden into time. He is 'thrown' into time in no time at all. ${ }^{21} \mathrm{He}$ has no present, initially. Moreover, he is in profoundly the wrong environment, socially, psychologically and physically (because the right environment would be: being exactly where Davidson is. Precisely. In the same place). Why then think that his thoughts would be one's/Davidson's thoughts, initially; or ever? At the instant of his creation, he would (we submit) have no meaningful thoughts at all, because he would not be in the present. Straight after his creation, his incipient thoughts might well be something like 'a blooming buzzing confusion', as every thought that sought to come into being from the state of his brain etc. clashed with almost every single perception of his (all his proprioceptions would be wrong, as well as all his visual perceptions; he would somehow struggle to reconcile the serious clash between his 'inherited' thoughts and his actual existence). Davidson has missed the nonnegotiable fact that his own spatial location crucially differentiates him from Swampman; and he has missed the non-negotiable philosophical fact that Swampman initially has no present. In terms of space and in terms of time, Swampman may be 'molecule for molecule identical' with Davidson, but this would in the quite ordinary sense of the words ${ }^{22}$ not give him the same thoughts as Davidson. It would in the quite ordinary sense of the words not give him (even a simulacrum of) Davidson's personal identity; far from it. The coming into being of Swampman would not result in a creature contentedly going home to Davidson's study and writing papers about radical interpretation. It would actually give rise to a kind of sad non-human monster: a being born in

\footnotetext{
19 James $(1890,631)$.

20 See also on this Harold Garfinkel's post-phenomenological (Wittgensteinian) thinking: as explicated at pp.106-7 of Read (2007).

21 See e.g. Rupert Read's argument, in Part 3 of his (2007), for why this does not make sense. (See also Read (2003) for more on this specifically).

22 As opposed to the (merely?) technical sense in which Davidson wants to withhold words like "recognise" from Swampman. (If Swampman actually can mimic Davidson perfectly, are we certain that we will want to withhold from him the application of such terms, even if we come to know about certain bizarre happenings in the swamp? Cf. n.2, above).
} 
total confusion, even insanity. Swampman understood aright is a kind of philosophical Frankenstein. There would never be even a moment in which Davidson's and Swampman's minds were the same, and Swampman's behaviour would quite possibly diverge radically and permanently from what Davidson's behaviour would have been, had he not been struck by lightning.

Davidson aspired to a new, strong form of externalism. We can now see a crucial respect in which his stance re Swampman is not 'externalist' enough.

It might be objected that it is not clear that Swampman's coming into existence as a physical replica of Davidson, albeit in a different part of the swamp, would be experientially any different from Davidson's losing consciousness in the lightning strike, being knocked (unconscious) into a different part of the swamp and then regaining consciousness unharmed. In both Davidson's and Swampman's cases, there might be some momentary and identical disorientation, but, unless there is something spooky going on, both would resume/commence their lives in identical ways; wouldn't they? And it is true that a proper Externalism will take one at least some distance along this track: One's perceptual organs will tend instantly to start to respond to the environment one is actually in. But there is a limit to this. For now, recall: Swampman is supposed to be created in and at the very instant that Davidson is snuffed out. And in an instant, in literally no time at all. This has to be so, otherwise there would be a clear physical (not to mention mental) difference between the two of them; for, if Swampman came into existence gradually if, e.g. he gradually gestated in the swamp - there would be the emergence into being of his thoughts in a manner having no parallel whatsoever in Davidson's existence, and apart from anything else this would tip Swampman off that he wasn't Davidson (and this again is why Swampman cannot be allowed to take time to come into being). There is - there can be - no gap, no time for Swampman to move from one place to another. By hypothesis, he wouldn't have moved from one place to another: he would simply have arisen in his new place. Spontaneously, and completely. So; Swampman's disorientation would be much more profound than this objection suggests. Swampman would

(a) allegedly come into existence entirely of a sudden: on this see the remarks about (his not being in) 'The Present', above; and

(b) be placed in the swamp in a way that radically contradicted the existing state of his visual and proprioceptive systems. For $100 \%$ physicalist identity requires that all one's actual registered perceptions and proprioperceptions and chronoperceptions and all one's thoughts and knowledge about these be as they were for Davidson. Swampman is - by Davidson's hypothesis - physically identical with Davidson: all this information about his location, his comportment etc. insofar as it had any bodily manifestation / any internalist encoding whatsoever would be wrong. This would we think 
already be a problem for a chimp; it might not be a terminal problem for a dog; and it certainly wouldn't be for a tick: So, no difficulty in imagining 'Swamptick' then. But Swampman?

Now, there is one (and only one) way in which one might save Davidson's thought-experiment, repair it from these otherwise fatal two flaws. If, when Davidson suddenly ceases to exist, Swampman were to come into being not somewhere else in the swamp, but in the exact same place as Davidson had been. And if, rather than having initially no present because having no past, Swampman were to have Davidson's past. If we place Davidson and Swampman so closely adjacent that there is no gap between the one and the other. The final Davidson time-slice processes seamlessly into the first Swampman time-slice. But of course, you see what we have done here. Swampman has now become nothing more than a new name for Davidson: and an entirely arbitrary one. Davidson, by another name. To save the thoughtexperiment, we had to destroy the thought-experiment.

\section{Resume'}

Let us take stock. Like a number of Davidson's interpreters, Lepore and Ludwig seek to take seriously the emphasis on the diachronic that motivates Davidson's very introduction of the Swampman thought experiment. But neither they nor he take it seriously enough. We have suggested that it is not clear that there can be a dimensionless time-slice physicalist account of the ordinary physical universe that is even remotely complete, even physically. It is not clear that Swampman and Davidson are truly identical even in a physical sense, once we put a question-mark over whether "physical" can be accurately equated with what can be milked from a dimensionless time-slice physicalist account.

In this sense, it is not even clear that Swampman can be intelligibly described. ${ }^{23}$ Incompatible desires go into his would-be description: the desire to have 'him' be molecule for molecule identical with Davidson, and the desire to have 'him' spring into entire existence in a dimensionless instant. These two desires appear to us mutually incompatible. (And if we are right in thinking that they are, then we have given a good reason for believing that what is being proposed when Swampman is proposed simply makes no sense. And, if it doesn't, then nothing has been successfully proposed.)

\footnotetext{
23 In this regard, Swampman has a close kinship with Dummett's scenario of objects spontaneously coming into and out of existence in different places; this scenario is critiqued in detail, from a resolute Wittgensteinian point of view, in Read and Cook (2007, 81-2).
} 
Even if we are wrong in that claim, however, we have argued that it is not clear that the desire for such an object to be a being is deliverable upon. Davidson says that Swampman will be behaviourally indistinguishable from him, and yet that Swampman cannot mean anything or have thoughts. Somewhat similarly, Goldberg $^{24}$ varies Davidson slightly by suggesting that Swampman must be an "epistemic zombie": that he cannot know what he means by the terms he uses. But we think that such ideas must be taken much more seriously. This isn't just about technicalities; this isn't about philosophical compliments being paid to or withheld from Swampman after the fact. It is ludicrous to talk about an epistemic or semantic zombie being behaviourally indistinguishable from Davidson. Thoughts are what is expressed; knowledge of meanings are present in things that are actually meant.

We think it entirely possible that an (alleged) being coming into existence all of a sudden, and 'programmed' quite wrongly, would truly not have thoughts. It wouldn't think anything, couldn't say anything, couldn't do anything. Or at least, if it could, then it certainly wouldn't just calmly go 'home' and write articles on radical interpretation.

We have suggested that (even if Swampman can be intelligibly imagined at all) Swampman will be very easily behaviourally distinguishable indeed from Davidson. He will at best be 'born' radically confused, and, while this radical confusion might get overcome, it equally might not. Swampman, for all anyone of us writing about the thought experiment 'before the fact' knows, may be permanently stuck in one might even risk terming a hitherto unknown form of insanity. In the Fregean sense, that is, perhaps Swampman really would not have thoughts.

\section{Conclusions}

Finally, then, let us reiterate (and re-examine) the nature of what Davidson allows and claims in his story: Davidson's "Swampman" has, according to Davidson, a brain which, in best-physicalist fashion, is structurally absolutely $100 \%$ identical to that which Davidson had, and will thus, presumably, behave exactly as Davidson would have. He will walk out of the swamp, return to Davidson's office at Berkeley, and write the same essays he would have written; he will interact like an amicable person with all of Davidson's friends and family, and so forth.

'Swampman' may be molecule for molecule identical with Davidson, but such identity simply does not yield any identity of thoughts. This, without any dualism or similarly dubious supernaturalistic manoeuvre whatsoever. But rather just a

24 Goldberg $(2012,160)$. 
proper understanding of the way in which thinking ain't just in the head, and of the nature of time as, necessarily, lived. The premise (and consequences) of Davidson's scenario that are italicised just above just ought not to have been accepted. The initial move in the conjuring trick is the one that fooled us.

Davidson, fails to comprehend how deep the 'internal' effects go of the allegedly 'external' being altered in respects that he misses, between himself and Swampman. Who we are crucially depends on where we are,$^{25}$ and where (and if!) we were before. The 'External' profoundly influences the Internal. Davidson thinks he has acknowledged this, by emphasising the deviant causal history of Swampman. But he hasn't looked nearly deeply enough into the phenomenological conditions of non-pathological experience. (And nor, so far as we can tell, has anyone else in 'the literature' since.) He has rashly assumed that he can help himself to a 'time-slice' conception of reality. He has not thought nearly deeply enough about our through-and-through contextual and lived spatio-temporal nature.

Wittgenstein thought it unhelpful (to do as Davidson - and Goldberg - does; namely:) to take knowledge of one's own mind as having in the normal case anything serious in common with knowledge of others' minds. Not because my knowledge of my own mind is so much 'better', but because it cannot be said of me, except as a joke, that I know that (say) I'm in pain (PI 246). In the pathological case, one can come to learn things about one's mind: e.g. that one is suffering from a pathology; if one is lucky. This is the very best that Swampman can hope for. To painfully come to understand the bizarreness of being molecule for molecule identical with a being that he is not (and that no longer exists). More likely, his experience would simply be and quite possibly remain or indeed become more radically confused and malformed. (Wittgenstein - or Bergson ${ }^{26}$ - would, we think, have thought about Swampman in roughly the kind of way laid out here.)

The final moral of the story of this story of Davidson's is that there is something hitherto-unsuspected wrong with physicalism. Without any supernaturalism or Mentalism whatsoever, we have shown here that molecule for molecule identity buys one far less even than someone like Davidson thinks. Swampman will not be the same as Davidson at the moment of his creation, because he will have no Present. From that initial non-identity, he may well diverge still further, and rapidly, as he responds to the clash between his physical identity (which includes radically wrong information about his comportment and location: "I'm standing by exactly THIS (especially elegant - or swampy) tree"; etc. etc.) and his actual comportment and location. Swampman's thoughts, while supervening on a shared physical substrate, will be neither instantly nor thereafter the same as Davidson's; probably far from it. Swampman might

\footnotetext{
25 See once more Read (2012).

26 Or Merleau-Ponty, or Heidegger.
} 
recover from his initially unworlded state. But that cannot be assumed. Physicalism is inadequate at least as a theory of us, because it cannot understand why that cannot be assumed. It thinks, mistakenly, that adherence to some hopeless antiscientific theory of mind is needed in order to suppose something like what we have laid out herein. When all that is actually needed is: to understand how we are who we are because of our continuity and because of our context.

One still might ask: 'But at the end of the day what does all this really matter? Isn't the amount of ink spilt over 'Swampman' out of all proportion to its (lack of any very great) significance in Davidson's work?' 27 Our answer is that there are at least three reasons why it is significant, and is worth getting right:

i) We have given reasons above for why reconsidering Swampman helps us to see what misfires in Davidson's philosophy of mind (and in his views on 'self-knowledge'). The actual nature of 'being-in-the-world'; the central importance of indexicality and context; getting what's true in externalism right (and taking it seriously enough); getting the nature of 'self-knowledge' (and its deep difference from ordinary knowledge) right: all of these are helpfully highlighted by thinking through Swampman.

ii) The Swampman thought-experiment cannot be undertaken, it turns out, without commitment to a deeply-dubious, widespread 'dimensionless timeslice' conception of the universe (and, by extension, of life). This conception needs to be extirpated.

iii) And lastly: It is true that the sheer amount of attention given to Swampman in the literature is daunting and probably excessive. Why has it received so much attention? Because it is a (fun-sounding, attention-grabbing) thoughtexperiment - and Analytic philosophy is obsessed with thoughtexperiments. But what is shown here in our article is a clear for-instance of why the very idea of (standard) thought-experiments is wrong. The very idea of stripping things down to some 'simple', lurid/weird model points us in the wrong direction, philosophically. What we actually need are wellworked out scenarios (as one finds in films and literature ${ }^{28}$ ), or deliberately self-deconstructing 29 'thought-experiments' (as one finds in Wittgenstein; ${ }^{30}$ imaginary scenarios that helpfully self-deconstruct, rather than constituting substantive philosophical resources that one can help oneself to). For what we find, when we look deeply into Swampman, is that one indeed has to look deeply into Swampman, more deeply than Davidson does by far, and more deeply than most of 'the literature' on him in order to see that, like so

\footnotetext{
27 As Davidson himself appears to think, since he apparently expressed regret over ever having invented Swampman (see Glüer 2011, 124).

28 See eg. Read (2012), or Cavell (1972, 1981).

29 That is 'therapeutic' / 'liberatory'.

30 See e.g. the treatment of Wittgenstein's 'woodsellers' thought-experiment in several papers in Crary and Read (2000) and of his 'two-minute-England' in Read and Woolley (2013).
} 
many other 'great' thought-experiments, 'Swampman' does not actually make sense. The thought-experiment, like so many others before it, collapses under its own weight. That is the last and possibly most important point of all that one can learn by reconsidering Swampman: that Davidson can't even put his question, and so much the worse for such 'thoughtexperiments'. ${ }^{31}$

\section{References}

Cavell, S. (1972). The Senses of Walden. Chicago: The University of Chicago Press.

Cavell, S. (1981). Pursuits of Happiness. The Hollywood Comedy of Remarriage. Cambridge: Harvard University Press.

Crary, A., Read, R. (2000). The New Wittgenstein. Oxon: Routledge.

Davidson, D. (1970). “Mental Events.” In Davidson (2001a), pp. 207-224.

Davidson, D. (2001a). Essays on Actions and Events. Oxford: Oxford University Press.

Davidson, D. (2001b). Subjective, Intersubjective, Objective. Oxford: Oxford University Press.

Davidson, D. (1984). Inquiries into Truth and Interpretation. Oxford: Clarendon Press.

Glüer, K. (2011). Donald Davidson: A Short Introduction. Oxford: Oxford University Press.

Goldberg, N. (2012). "Swampman, response-dependence, and meaning", in G. Preyer (ed.), Donald Davidson on Truth, Meaning and the Mental. Oxford: Oxford University Press, pp. 148-163.

James, W. (1890). The principles of psychology. New York: H. Holt and Company.

Kallestrup, J. (2012). Semantic Externalism. London and New York: Routledge.

\footnotetext{
31 Many thanks to Gareth Jones for remarks that helped inspire this paper and for comments on an earlier version of it. And to Angus Ross for comments that have greatly improved it. Thanks also to a helpful anonymous referee.
} 
Kuhn, T.S. (1970). "Reflection on my Critics" in Lakatos, I., Musgrave, A. (1970) Criticism and the Growth of Knowledge, Cambridge: Cambridge University Press, pp. 231-278.

Lepore, E. And Ludwig, K. (2005). Donald Davidson. Meaning, Truth, Language, and Reality. Oxford: Oxford University Press.

Putnam, H. (1975) "The Meaning of Meaning." In Mind, Language and Reality; Philosophical Papers Volume 2. Cambridge: Cambridge University Press, pp. 215-271.

Read, R. (2003). “Against 'Time-slices”, Philosophical Investigations 26(1): 2443.

Read, R. and Cook, L. (2007). Applying Wittgenstein. London and New York: Continuum.

Read, R., Woolley, J. (2013). "Review of James C. Klagge. Wittgenstein in Exile", Journal of the History of Philosophy 51(3): 499-500.

Wittgenstein, L. (2001). Philosophical Investigations. G. E. M. Anscombe, trans., Oxford: Blackwell. 